\title{
Impact of socio-demographics on Malocclusion and Traumatic dental injuries among 13-15 years old children in province II of Nepal
}

\author{
Dr Rahul Gupta,' Dr Swagat Mahanta, ${ }^{2}$ Dr Rishi Pratap Sah³ \\ 'Assistant Professor, Kedia Dental College And Teaching Hospital, Birgunj, Nepal, \\ 2Lecturer, Kathmandu University School of Medical Sciences, Dhulikhel, Nepal, \\ ${ }^{3}$ Assistant Professor, Janaki Medical College And Teaching Hospital, Janakpur, Nepal \\ Correspondence: Dr Rahul Gupta ; Email: dr.rrahul@yahoo.com
}

\section{ABSTRACT}

Introduction: Malocclusion may not be pathological condition, but it negatively affects the quality of life. The purpose of the study was to assess the role of socio-demographics on malocclusion and traumatic dental injuries among adolescents.

Materials \& Method: A cross-sectional descriptive study was conducted with a sample of 320 students from government and private schools. Student's in the age range from 13-15 years were included. A structured questionnaire was used to assess demographic characteristics, socio-economic status, frequency of dental visit and tooth brushing, self-perceived need for orthodontic treatment. Index of orthodontic treatment need (IOTN) and Traumatic Dental Injury (TDI) were recorded.

Result: The study showed that self-reported orthodontic treatment need was greater among Private school students as compared to Government. IOTN-DHC more severe Grade 4, Grade 3 type of treatment needs were greater among government students. While Grade 1 \& Grade 2 type of treatment needs was found to be greater among private students. Grade 5 \& Grade 4 type of orthodontic treatment needs was greater among government students, 83(51.9\%) \& 48 (30\%) as compared to private students, $21(13.1 \%)$ \& 25(15.6\%). While Grade 1, Grade 2 \& Grade 3 type of orthodontic treatment needs was lesser among government students, $6(3.8 \%), 8(5.0 \%) \& 15(9.4 \%)$ as compared to private students, $42(26.2 \%), 49(30.6 \%) \& 23(14.4 \%)$ respectively. Complicated type of dental injury was greater among government students.

Conclusion: The study indicates the presence of socio demographic gradient in orthodontic treatment need and Traumatic dental injuries.

Keywords: IOTN, Malocclusion, Socio demographics, Traumatic dental injury.

\section{INTRODUCTION}

Malocclusion causes psychological disturbances related to impaired dento-oro-facial esthetics. Malocclusion may not be pathological condition, but it negatively affects the quality of life. Malocclusion has varying prevalences in different countries. Sociodemographic makes an impact in the need of orthodontic treatment. The psychosocial impact of dental esthetics is an important component of health related quality of life (OHRQOL).' The factors affecting OHRQoL among the adolescent is important for optimizing the effects of orthodontic treatment.' The association severity of malocclusion and psychosocial impact is usually modest. However understanding and assessing the social impact of dental esthetics among children and adolescent is complex. The IOTN was developed to measure treatment need in people or groups to ensure the patients with greatest need receive treatmentand to aid in the orthodontic treatment manpower planning. Although the index measure outcomes relavent to malocclusion traits, they might not be totally relavent to consumers. ${ }^{2}$ Many patients who may need orthodontic treatment according to index of orthodontic treatment need may reject clinical treatment. It may be possible that these patients think that the benefits of orthodontic treatment is not balanced. ${ }^{3}$ The purpose of the study was to assess the role of socio-demographics on malocclusion and traumatic dental injuries among adolescents. This further determines their acceptance of orthodontic treatment.

\section{MATERIALS AND METHOD}

A descriptive cross-sectional study was conducted in province II of Nepal. A sample of 320 students were taken into study, 6 government schools and 6 private schools were randomly selected. 160 students from 6 government school and 160 students from 6 private 
school, were included into study. Sample size was estimated and Students studying in standard 7 to standard 9, of age ranging from 13-15 were taken into study. Inclusion criteria for the respondents were age at the time of the study (13-15 years). All the respondents were asked to produce their birth certificates to verify their age. All 320 children who agreed to participate were included in the study. Children with developmental defects of oral cavity were excluded from the study. A pre-structured questionnaire was given to those students in the classroom.

Questionnairewas divided into 4 sections, the first section asked for demographic characteristics, particularly age, sex, class, type of school (government/private). Second section dealt with modified kuppaswamy's socio-economic scale, ${ }^{4}$ which included information about, (1) Education of the head of the family, (2) Occupation of the head of the family, (3) Total family income, (4) Socioeconomic status was to be derived with above information.

Third section included the questions (1) Frequency of dental visit, (2) Daily frequency of tooth brushing,

(3) Do you think you need orthodontic treatment.

This section also concerned the respondents about their perception of malocclusion which represented aesthetic component (AC) of the index of orthodontic treatment need (IOTN). 5 The AC rates a person's attractiveness on 10 -point scale, illustrated by intraoral photographs. The (DHC) dental health component of IOTN was also determined in grades. Thereafter orthodontic treatment need was derived.
In the fourth section traumatic dental injury based on Glendor et al-1996 ${ }^{\circ}$ was recorded if present. it was recorded in terms of uncomplicated and complicated fracture of anterior teeth.

\section{RESULT}

The study was performed on both Government and Private school type among which 160 (50\%) students participated from Government School while rest 160 (50\%) participated from Private. The mean age of students was $14.07( \pm 0.71)$.

The study showed that the frequency of dental visit was greater among private school students as compared to the government students. The frequency of visit of once in a six months was found only among 3 (1.9\%) students from government School as compared to Private, 55 (34.4\%). Students who never visited the dentist was 96 (60\%) and 19 (35.9\%) respectively. These differences were found to be statistically significant $\mathrm{p}<0.01$.

The study showed that frequency of toothbrushing was greater among Government students as compared to Private students. The frequency of tooth brushing once a day was $122(76.2 \%)$ among Government Students as compared to Private, 67 (41.9\%). While students those who brush twice a day was greater in private, 87 (54.4\%) as compared to Government, 37 (23.1\%). These differences were found to be statistically significant $\mathrm{p}<0.01$.

The study showed that the students self reported for orthodontic treatment needs was greater among Private students as compared to Government students. The self reported orthodontic treatment needs was

Table 1: Frequency of dental visit among government and private school children.

\begin{tabular}{|l|c|c|c|c|c|c|}
\hline \multicolumn{7}{|c|}{ Frequency of dental visit } \\
\hline School Type & Once in six months & Once in a year & Infrequent & Never & Chi square & P value \\
\hline Government & 3 & 55 & 6 & 96 & 104.066 & $0.01^{*}$ \\
\hline Private & 55 & 71 & 15 & 19 & & \multirow{2}{*}{. } \\
\hline
\end{tabular}

Table 2: Frequency of tooth brushing among government and private school children.

\begin{tabular}{|c|c|c|c|c|c|}
\hline \multicolumn{6}{|c|}{ Tooth brushing frequency } \\
\hline School Type & Once a day & Twice a day & More than twice a day & Chi square & $P$ value \\
\hline Government & 122 & 37 & 1 & \multirow{2}{*}{43.167} & \multirow{2}{*}{$0.01^{*}$} \\
\hline Private & 67 & 87 & 6 & & \\
\hline
\end{tabular}

Table 3: self-reported orthodontic treatment need among government and private school children.

\begin{tabular}{|l|c|c|c|c|}
\hline \multicolumn{1}{|c|}{ School Type } & Self reported orthodontic treatment need & Chi square & P value \\
\hline Government & 64 & No & 95 & 15.072 \\
\hline Private & 98 & 63 & $0.01^{*}$ \\
\hline
\end{tabular}


Table 4: IOTN-DHC

\begin{tabular}{|c|c|c|c|c|c|c|}
\hline \multicolumn{7}{|c|}{ IOIN- DHC } \\
\hline School Type & Grade 1 & Grade 2 & Grade 3 & Grade 4 & Chi square & $P$ value \\
\hline Government & 3 & 55 & 6 & 96 & \multirow{2}{*}{98.248} & \multirow{2}{*}{$0.01^{*}$} \\
\hline Private & 55 & 71 & 15 & 19 & & \\
\hline
\end{tabular}

Table 5: complicated and uncomplicated traumatic dental injury in government and private school children.

\begin{tabular}{|l|c|c|c|c|c|}
\hline \multicolumn{7}{|c|}{ Traumatic Dental Injury } \\
\hline School Type & Uncomplicated & complicated & No injury & Chi square & P value \\
\hline Government & 50 & 87 & 23 & $58.879 \mathrm{a}$ & $0.01^{*}$ \\
\hline Private & 79 & 23 & 58 & & \\
\hline
\end{tabular}

Table 6: orthodontic treatment need among government and private school children.

\begin{tabular}{|c|c|c|c|c|c|c|c|}
\hline \multicolumn{7}{|c|}{ Orthodontic treatment need } & \multirow[b]{2}{*}{$P$ value } \\
\hline School Type & Grade 1 & Grade 2 & Grade 3 & Grade 4 & Grade 5 & Chi square & \\
\hline Government & 6 & 8 & 15 & 48 & 83 & \multirow{2}{*}{102.384} & \multirow{2}{*}{$0.01^{*}$} \\
\hline Private & 42 & 49 & 23 & 25 & 21 & & \\
\hline
\end{tabular}

98 (61.2\%) from Private students as compared to Government, 64(40\%). These differences were found to be statistically significant $\mathrm{p}<0.01$.

In the study, IOTN-DHC more severe (Grade 4) type of treatment needs was greater among government students, $12(7.5 \%)$ as compared to private students, 8 (5\%). Again severe (Grade 3) type of treatment needs was greater among government students, 107 (66.9\%) as compared to private students, 34(21.2\%). While Grade 1 \& Grade 2 type of treatment needs was found to be greater among private students, 55(34.4\%) \& $63(39.4 \%)$ as compared to government students, 0 $\& 41(25.6 \%)$ respectively. These differences were found to be statistically significant $p<0.01$.

The study showed that Grade 5 \& Grade 4 type of orthodontic treatment needs was greater among government student, $83(51.9 \%)$ \& $48(30 \%)$ as compared to private students, 21 (13.1\%) \& 25(15.6\%). While Grade 1, Grade 2 \& Grade 3 type of orthodontic treatment needs was lesser among government students, $6(3.8 \%)$, $8(5.0 \%) \& 15(9.4 \%)$ as compared to private students, $42(26.2 \%), 49(30.6 \%) \& 23(14.4 \%)$ respectively. These differences were found to be statistically significant $p$ $<0.01$.

Traumatic dental injuries were evaluated among the study participants. Complicated type of dental injury was greater among government students, 87(54.4\%) as compared to private students, 23(14.4\%). While uncomplicated type of dental injury was lesser among government students, $50(31.2 \%)$ as compared to private students, $79(49.4 \%)$. And students with no any traumatic dental injury was lesser among government students, 23(14.4\%) as compared to private students, $58(36.2 \%)$. These differences were found to be statistically significant $p<0.01$.

\section{DISCUSSION}

The provision of orthodontic treatment is not life saving but it can often be life changing since malocclusion is an important factor in determining the perception of a person ' s intelligence and attractiveness by peers and the wider public ( Shaw, 1981 ).

Physical appearance can have an impact on the self esteem of every human being. Properly aligned teeth can have a positive impact, and irregular or protruded teeth can have a negative impact. ${ }^{7}$

The perception of beauty is a highly subjective phenomenon. Perception is defined as the process by which patterns of environmental stimuli are organized and interpreted and can be influenced by a variety of physical, physiological, psychological, and social factors. ${ }^{8}$

The mean age of the study participants was 14 years, this age group was chosen as previous research into decision making has suggested that children below the age of 10 years have difficulty in making decisions concerning aesthetic improvement. ${ }^{\text {? }}$

Perception can vary among individuals, races, and sexes. Moreover, the perception of the clinician or orthodontist may not match with the perception of the patient. 
The IOTN has been widely used in epidemiological studies of malocclusion for prioritizing treatment needs and to plan the resources in order to avoid wastage of expenditure.

The present study has shown a social gradient in the pattern of malocclusion, where the children from the government schools showed a higher need for orthodontic treatment as evaluated by using DHC of the IOTN. Some researcher had found that malocclusion was more severe in preadolescent school children from lower socioeconomic background, indicating social disparities in oral health. ${ }^{10}$

Parental levels of education and lower SES could be a factor in the prevalence of malocclusion of their children. Lack of attention towards the oral health of the child and irregular dental visits could be a reason to explain such a finding.

- There were studies stating that individuals with precarious social and economic status as well as in poor mental condition due to poor living standards tend to negatively impact the way these individuals raise and educate their offspring."

In the study done by Hamdan et al, Total demand for orthodontic treatment was considerably greater than self assessed "definite" and "borderline need". ${ }^{2}$ (A.M.
Hamdan, ' V. Singh and W.P. Rock, Assessment of the relationship between perceptions of dental aesthetics and demand for orthodontic treatment in $10-11$ year old school children in Birmingham, UK. Community Dental Health, this finding was similar to the findings in our study. ${ }^{12}$

Children from the government school reported higher perceived orthodontic treatment need as compared to private school students. This finding corresponds to the finds of suresh et al and badran et al where public school students were 2.60 (1.64-4.63) times more likely to report perceived need for treatment compared to adolescents from private school. This could be due to their lower satisfaction of dental appearance. 13, 14

\section{CONCLUSION}

The study showed significant impact of socio-demographics on malocclusion among the children of government and private school. The frequency of dental visit, tooth brushing twice a day, student self- reporting for orthodontic treatment need was greater in private school children, whereas tooth brushing only once a day, complicated type of dental injury was greater in government school children.

\section{OJN}

\section{REFERENCES}

1. Deng X, Wang YJ, Deng F, Liu PL, Wu Y; Psychological well-being, dental esthetics, and psychosocial impacts in adolescent orthodontic patients: A prospective longitudinal study. Am J Orthod Dentofacial Orthop. 2018 Jan;153(1):87-96

2. Mandall NA, Wright J, Conboy F, Kay E, Harvey L, O'Brien KD; Index of orthodontic treatment need as apredictor of orthodontic treatment uptake. Am J Orthod Dentofacial Orthop. 2005 Dec;128(6):703-7

3. Lin F, Ren M, Yao L, He Y, Guo J, Ye Q; Psychosocial impact of dental esthetics regulates motivation to seek orthodontic treatment; Am J Orthod Dentofacial Orthop. 2016 Sep;150(3):476-82

4. Kuppuswamy B. Manual of Socioeconomic Status (Urban) 1st ed. Delhi: Manasayan; 1981. pp. 66-72.

5. Brook PH, Shaw WC; The development of an index of Orthodontic Treatment Priority. Eur J Orthod 1989;1 1:309-20.

6. Pagadala S, Tadikonda DC. An overview of classification of dental trauma. IAIM, 2015; 2(9): 157-164.

7. Albarakati SF; Self-perception of malocclusion of Saudi patients using the aesthetic component of the IOTN index. Pak Oral Dent J $2007 ; 27: 4551$.

8. Lindsay SJ, Hodgkins JF; Children's perceptions of their own malocclusions. Br J Orthod 1983;10:13 20.

9. Shaw WC; Factors influencing the desire for orthodontic treatment, Eur J Orthod. 1981;3(3):151-62

10. Hanna A, Chaaya M, MoukarzelC, El Asmar K, Jaffa M, Ghafari JG; Malocclusion in elementary school children in Beirut: severity and related social/behavioral factors. Int J Dent. 2015;2015:351231.

11. Blackburn C. Poverty and health: working with families, Buckingham: Open University Press; 1991.

12. A.M.Hamdan, V. Singh and W.P. Rock; Assessment of the relationship between perceptions of dental aesthetics and demand for orthodontic treatment in $10-11$ year old school children in Birmingham, UK. Community Dental Health (2011) XX, 1-5.

13. K Suresh, Manjunath C, A Krishnamurthy, S K Mahanta, S Mallick, M Das. What Sociodemographic factors Influence the Perceived Orthodontic treatment need among Adolescents in Kottayam city- a Cross-Sectional Study. Adv. Biores., Vol 8 [1] January $2017: 25-30$.

14. Badran SA, Sabrah AH, Hadidi SA, Al Khateeb S; Effect of socioeconomic status on normative and perceived orthodontic treatment need. Angle Orthodontics 201484 (4): 588-93. 